Bull. Mater. Sci., Vol. 3, Number 1, February 1981, pp. 67-73. Printed in India.

\title{
Influence of impurities on chemical etch pits in gypsum single crystals* $^{*}$
}

\author{
K S RAJU \\ Department of Physics, Madras University Post-Graduate Centre, \\ Coimbatore 641 041, India \\ Present address: Department of Biophysics and Crystallography, University of \\ Madras, Guindy Campus, Madras 600 025, India \\ MS received 18 July 1980
}

\begin{abstract}
Basal cleavages of gypsum are etched in nitric acid and potassium hydroxide solution. Terraced pits are commonly observed independent of the etchants used. Varying degrees of widths of terraces are observed on etching matched cleavage pairs as well as thin flakes. The terraced nature of etch pits has been attributed to the inhibitive action of the etchant due to the precipitation of impurities along dislocation lines. On prolonged etching of a thin flake holes are formed at some dislocation sites while at ather dislocation sites, holes are not formed. Preferential etching of fission tracks gives rise to winged etch pits. The implications are discussed.
\end{abstract}

Keywords. Terraced pits ; winged pits; impurity precipitation in gypsum.

\section{Introduction}

Studies on different types of etch pits and their density give useful information regarding the nature of defects, impurity content and the history of growth of crystals. In the case of calcite and mica it has been conjectured that the terraced nature of pits is due to the precipitation of impurities along dislocation lines. (Patel and Goswami 1963; Patel and Ramanathan 1963). It is quite probable that the fission fragment lying along the dislocation line may deviate the geometrical shape of the etch pit due to the preferential etching along the fission track giving rise to a groove or a wing shape to the etch pit. Fleischer et al (1964) attributed the anomalous nature of etch pits to the dissolution of fission fragments present in the body of the crystal. Lovell (1958) and Patel et al (1967) reported the anomalous nature of etch pits in apatite as due to the existence of fission fragments in the crystal. From the geometrical shape and arrangement of etch pits, the evidence of edge and screw dislocations in gypsum has been reported by Raju (1980).

* Contribution No, 549. 
In the present paper, an attempt is made to investigate the nature and shape of etch pits on etching (i) isolated, (ii) matched pairs and (iii) thin flakes of (010) faces of gypsum with analar grade nitric acid and $0.1 \mathrm{~N}$ potassium hydroxide solution.

\section{Observations}

\subsection{Etching of isolated cleavages}

Figure 1 is the photomicrograph of the etch pattern on (010) cleavage face of gypsum etched in analar grade nitric acid for $4 \mathrm{~min}$ revealing the nature of etch pits formed. The pits are (i) point-bottomed and (ii) flat-bottomed, with narrow and wide terraces. Figure 2 reveals an asymmetric pit having non-uniform terraces.

\subsection{Etching of matched pairs}

To determine the reason for the terraced nature of pits described, matched counterparts of gypsum cleavages were etched for $10 \mathrm{~min}$ in analar grade nitric acid (figures $3 a, b$ ). Figures $4 a$ and $4 b$ are the etch patterns on another matched pair, when one face is etched in nitric acid and its counterpart in $0.1 \mathrm{~N}$ potassium hydroxide solution for the required period.

The following points are noteworthy : (1) Almost all the pits are terraced. (ii) There is a one-to-one correspondence in number and positioning of the pits. (iii) For a narrow-terraced pit on one face, there is a corresponding wide-terraced pit on the' matched face and vice versa. (iv) The nature of pits is terraced, irrespective of the etchants used.

\subsection{Etching of thin flakes}

Figures $5 \mathrm{a}$ and $5 \mathrm{~b}$ represent the etch patterns on the opposite sides of a uniformly thin gypsum flake. A careful study cf these patterns reveals the following : (i) The holes (black regions) have a one-to-one correspondence on both the opposite faces. (ii) The pits, where holes are not formed, are terraced and have a one-to-one correspondence.

Winged etch pits with an anomalous appearance are observed on etching gypsum cleavages. Figures $6 a$ and $6 b$ are the etch patterns on the opposite sides of a flake. It is seen that there is no correlation of the anomalous nature in the corresponding etch pits. No wings are seen on the face after silvering proving that the wings are air wedges inside the body of the crystal.

\section{Discussion}

The correspondence in the terraced nature of etch pits on matched faces, even when etched with different etchants, suggests that the terraces are formed due to the nature of dislocations and has nothing to do with the etchant used. The terraced nature can be explained by postulating the precipitation of some sort of 

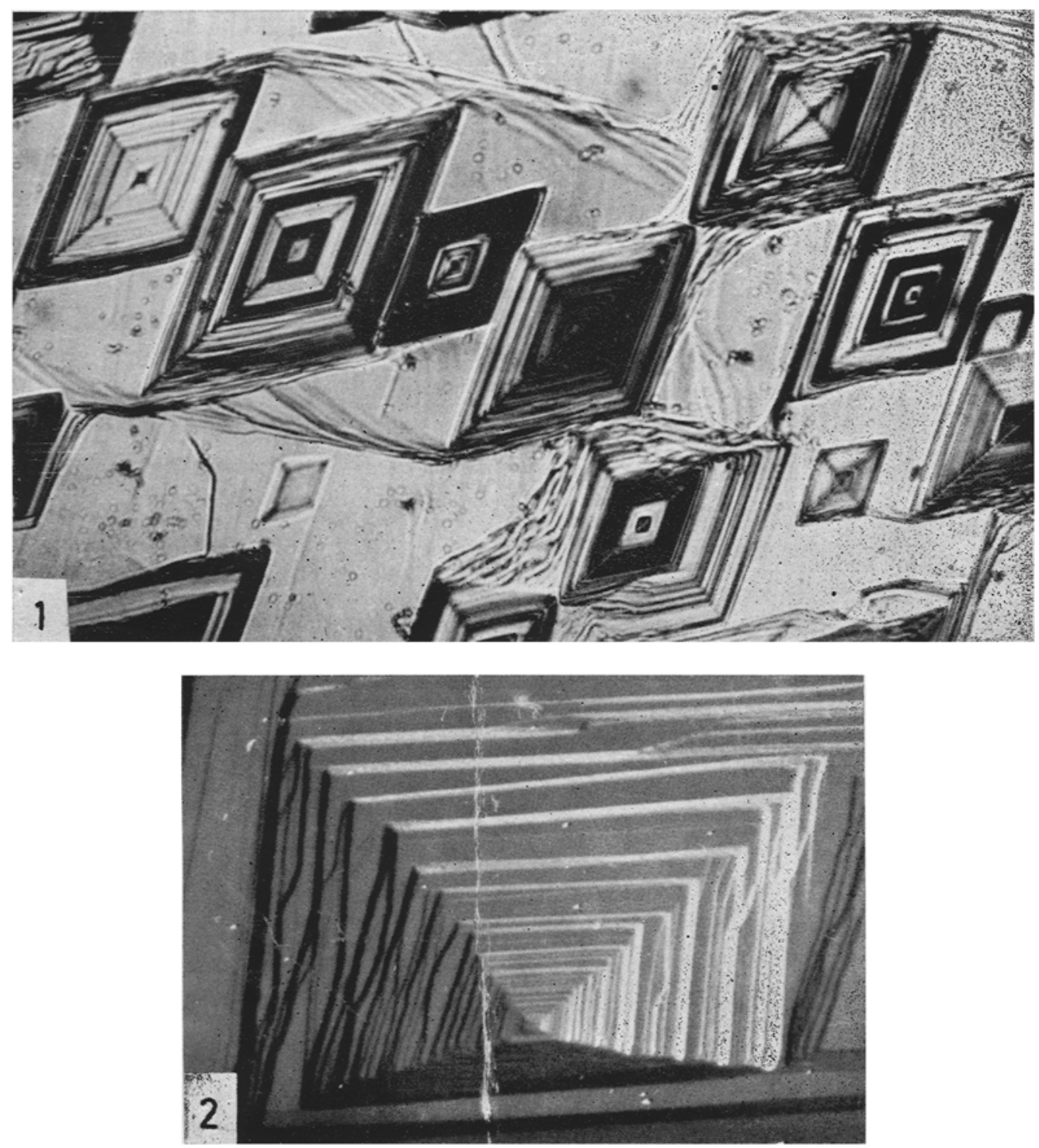

Figures 1-2. 1. Etch pattern revealing terraced pits $(\times 350)$. 2. Asymmetric terraced pit $(\times 1,500)$. 

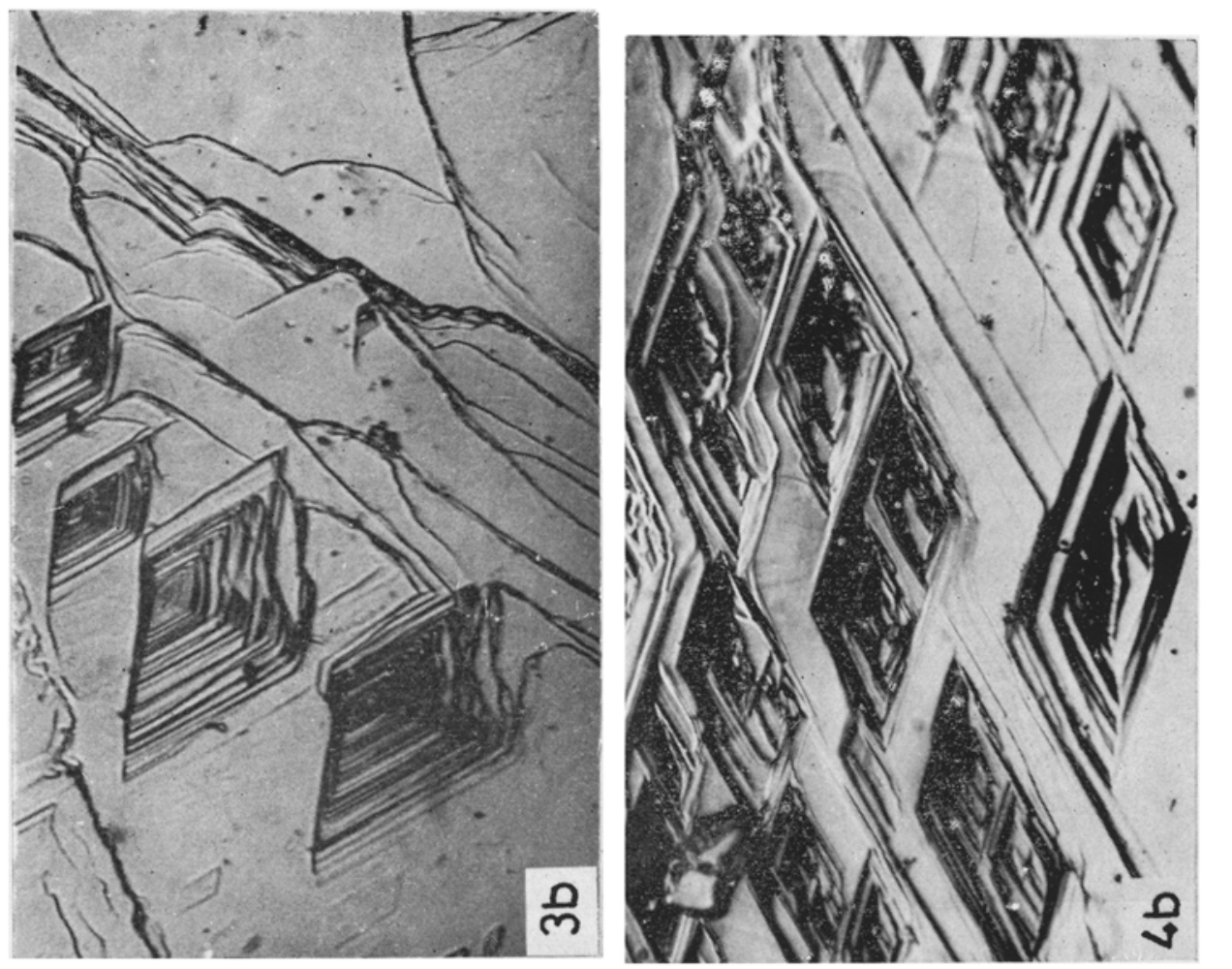

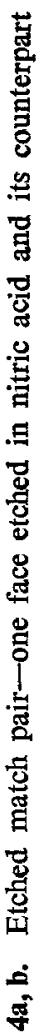
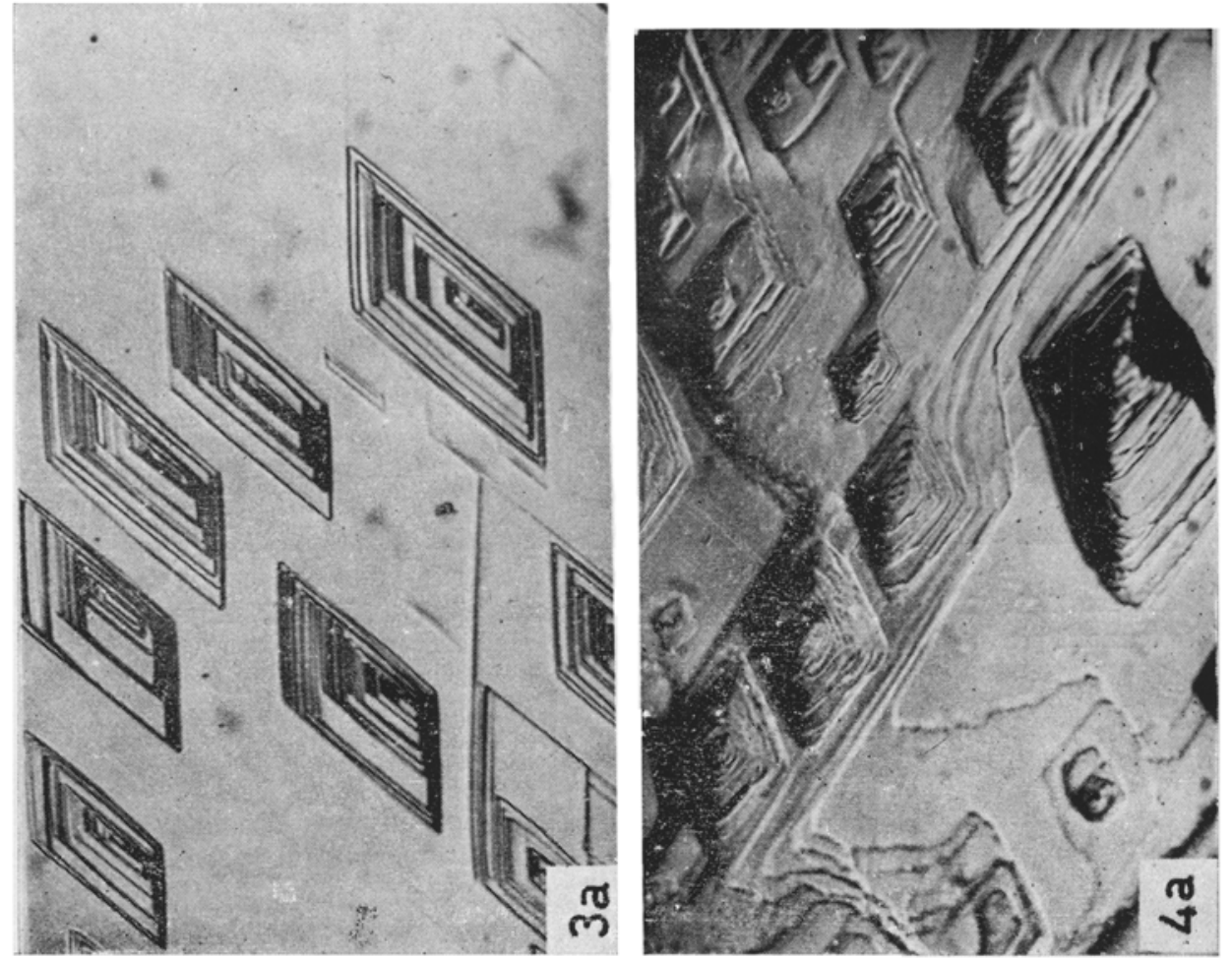

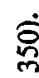

$x$

뮴

蒫

宅

옹

焉

氙

홍

四

s.

का

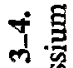

迳总 

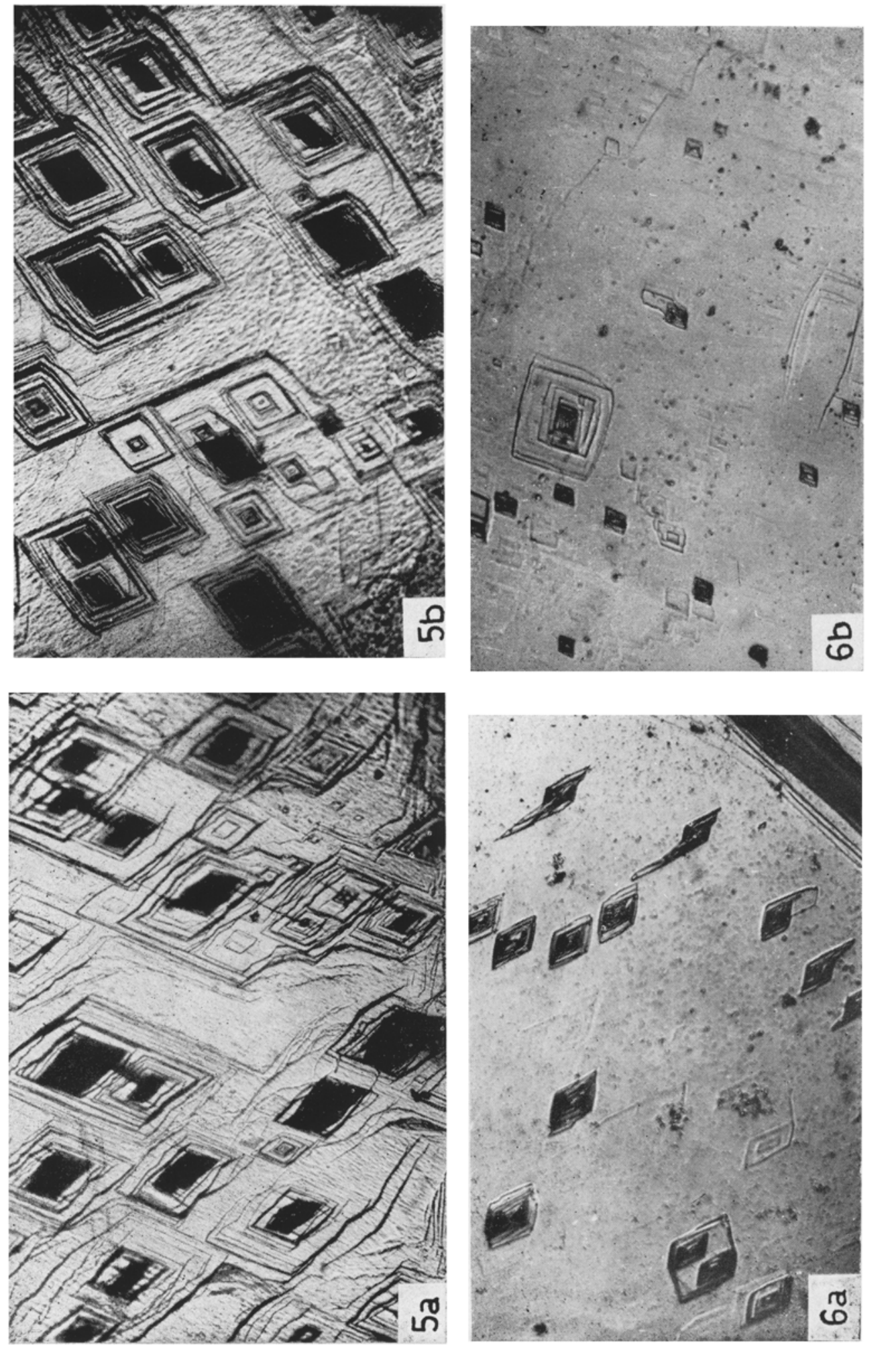

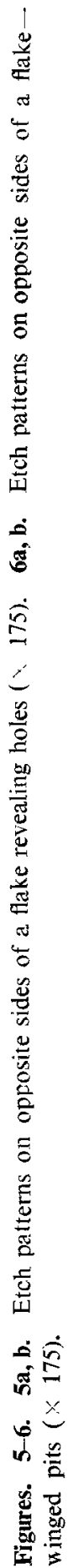


impurities along the dislocation line which mighi inhibit the action of the etchant depending upon the nature, density and location of such impurities. These impurities might be unevenly spaced along the dislocation lines which result in pits having various types of terraces. The number of times the inhibitive action is operated can be judged by the number of terraces. When the inhibitive action lasts longer, widely terraced pits are produced and if it lasts for a shorter period, narrowly terraced pits are produced.

When a uniform thin crystal flake is etched for a prolonged period, holes are produced at only specific sites, although the etch attack starts simultaneously from both sides. This suggests that at the sites where holes are not produced, some sort of inhibitive action may be taking place. This may be due to the precipitation of some impurities at these dislocation sites during the growth of the crystal, thus inhibiting the action of the etchant supporting the conjecture for the terraced nature of pits. This is further supported by the fact that the pits, where holes are not formed, are also terraced in nature.

The fact that winged pits on one face correspond to non-winged pits and that wings are air wedges in the body of the crystal, suggests that the sites of the pits indicate the usual dislocations. The formation of wings giving anomalous character to the pits can be explained by assuming the existence of fission tracks in the body of the crystal as observed by Fleischer et al (1964). On etching, when the pit grows larger and its boundary touches the fission track the etchant will etch the track and produce an air wedge in the body of the crystal. If a fission track lies near one dislocation on a cleavage face, it need not also necessarily lie near the corresponding dislocation line on the opposite side of the flake, so as to produce a correlation in the wing structure, as observed.

\section{Acknowledgement}

The author wishes to thank Prof. A R Patel, Department of Physics, Sardar Patel University, Vallabh Vidyanagar, for his encouragement.

\section{References}

Fleischer R L, Price P B and Symes E M 1964 Am. Miner. 49794

Lovell L C 1958 Acta Metall. 6775

Patel A R, Agarwal M K and Desai C C 1967 J. Phys. Soc. Jpn. 23553

Patel A R and Goswami K N 1963 Physica 2933

Patel A R and Ramanathan S 1963 Am. Miner. 48691

Raju K S 1980 Bull. Mater. Sci. 2139 